\title{
Patrimonio y memoria: encuentros y desencuentros por el hallazgo del cementerio muisca en la hacienda El Carmen, en Bogotá, D. C.
}

\author{
Heritage and memory: agreements and disagreements by the finding of \\ the muisca cemetery in Hacienda El Carmen, in Bogota, D. C.
}

\author{
Angie Tatiana Cardozo Rodríguez \\ Comunicadora social \\ Joven investigadora de Colciencias \\ atcr.atcr@hotmail.com
}

Artículo de reflexión

Fecha de recepción: 4 de octubre de 2013 • Fecha de aprobación: 1 de diciembre de 2013

\section{RESUMEN}

A propósito del hallazgo arqueológico del cementerio indígena muisca en la hacienda El Carmen de la localidad bogotana de Usme, el artículo problematiza la manera como la memoria y el patrimonio son apropiados por los diferentes actores sociales para avanzar en sus luchas políticas y sociales. Por ello, enfatiza sobre las alianzas y rivalidades que emergen a partir de la apropiación del escenario. También reconstruye la historia del territorio de la hacienda El Carmen sobre la base de sus hitos más conflictivos.

Palabras clave: patrimonio, territorio, comunicación, identidad, memoria

\section{Abstract}

About the archaeological find of muisca Indian cemetery in the El Carmen de Bogotá Usme, the paper we discuss how memory and heritage are appropriated by different social actors to advance their political and social struggles. Therefore it emphasizes alliances and oppositions 
that emerge towards the appropriation of the stage. It also traces the history of the territory of the El Carmen on the basis of its most controversial milestones.

Keywords: Heritage, territory, communication, identity, memory

\section{Presentación}

Dentro del proyecto de expansión urbana que lidera el Gobierno Distrital, la zona sur de la ciudad de Bogotá, en los bordes rurales de la localidad de Usme, Metrovivienda ${ }^{1}$ adelantaba en el año 2007 la construcción de viviendas de interés social en el territorio conocido como Hacienda el Carmen. En medio de los trabajos hallaron accidentalmente un cementerio Mhuysqa. Las treinta hectáreas de superficie que cubre la hacienda, más de un veinticinco por ciento, guarda en su subsuelo información de la comunidad aborigen ${ }^{2}$. A partir del hallazgo, en 2008 la entidad distrital y la Universidad Nacional de Colombia realizaron un estudio arqueológico cuyos resultados evidenciaron que las poblaciones que habitaron en el lugar correspondían al pueblo aborigen Mhuysqa, en un arco temporal de poco más de mil quinientos años. Los resultados oficiales de las instituciones a cargo del estudio fueron muy descriptivos, y no dio lugar al diálogo y a la participación de otro tipo de actores. Como suele suceder en el mundo de la vida cotidiana, el conocimiento científico se impuso sobre los saberes de los pobladores, pues la gestión que se realizó quedó bajo una única interpretación, emergiendo una serie de conflictos y tensiones entre los distintos actores involucrados, sobre todo en lo que atañe al manejo del hallazgo como un patrimonio de "todos".

Entre los conflictos generados a partir del estudio cabe destacar el que involucra, precisamente, a la comunidad Mhuysqa de Bogotá. Desde su perspectiva, la interpretación patrimonial dada por la institución no tuvo el debido manejo respecto

1 Organización de la Alcaldía Mayor de Bogotá que se encarga de la construcción y adquisición de vivienda de interés social en la ciudad.

2 Alguna de las piezas encontradas en las excavaciones fueron utensilios, fragmentos de talla, adornos como collares y dijes, materia prima como arcilla, restos óseos humanos y animales. También, se evidenciaron aspectos como la adecuación de terrenos - verbigracia, canales de desagüe y surcos. 
a la consulta que se debió realizar al territorio para realizar los estudios en cuestión. Dicho en palabras de uno de los líderes espirituales del cabildo Mhuysqa de Bosa, Edward Arévalo: "vienen a mi casa sin pedir permiso, entran y se llevan mis cosas, no es lo correcto, hay que consultarle al territorio, y ¿cómo se consulta el territorio? Desde el pensamiento" (2014).

Para la comunidad Mhuysqa, las excavaciones desordenaron el sitio y alteraron un orden lógico dado. Este lugar, como lo sostiene Edward Arévalo, era un lugar de ceremonia "donde descansaban los caciques y los mayores de la antigua Bacatá Mhuysqa. Este lugar es la sabiduria de la semilla del pensamiento, era un lugar no habitado, era un lugar de paso, donde los ancestros recogian la semilla de abundancia para el recorrido que debian emprender a otros santuarios del territorio Mhuysqa” (2013, p. 60).

Pero esta interpretación espiritual y ancestral también es discutida por otros actores que se declaran "dolientes" del territorio de Hacienda El Carmen. Se trata de los actuales habitantes de la zona, quienes hacen su particular lectura sobre el hallazgo arqueológico y utilizan estratégicamente el descubrimiento para expresar su inconformidad por las iniciativas de expansión urbana sobre las zonas rurales de la localidad. En consecuencia, el descubrimiento se convirtió para una serie de actores (líderes comunitarios de las áreas rurales, campesinos de la zona, movimientos sociales y organizaciones ambientales) en la oportunidad para intervenir en la defensa de un amplio territorio de la localidad con vocación rural/agrícola, rechazando cualquier política de expansión de la ciudad a través de planes de vivienda.

De cualquier modo, el patrimonio y la memoria se convirtieron en los caballos de batalla para que los actores involucrados intervengan políticamente en la discusión.

\section{Plan de expansión urbana en Usme}

La localidad de Usme se caracteriza por albergar en su territorio amplias zonas rurales con vocación agrícola. No obstante, desde hace más de una década la localidad cinco de Bogotá se convirtió en una de las zonas estratégicas para el desarrollo de la 
expansión urbana, modificando de manera drástica el paisaje y transformándolo en un escenario en el que coexiste lo rural y lo urbano.

Enrique Peñalosa en su primer mandato (1997 a 1999) buscó modernizar la ciudad de Bogotá, por medio del reordenamiento territorial, lo cual implicó aumentar el casco urbano de la urbe. Con el objetivo de cumplir lo anteriormente planteado, se creó Metrovivienda, institución encargada de gestionar y desarrollar la construcción de viviendas de interés social en los bordes de la zona sur de la ciudad. La entidad, entonces, puso en marcha ambiciosos proyectos de construcción, privilegiando las localidades de Bosa, Fontibón, Engativá, Suba con propuestas y planes industriales de comercialización, importación y exportación, mientras en la localidad de Usme, por ser en su mayoría zona rural, se buscó proyectos de vivienda multifamiliares.

Para el caso de Usme, el plan de expansión se materializó en la alianza estratégica entre Metrovivienda y la Asociación de Vivienda Popular Simón Bolívar, donde la primera aportó los costos de urbanismo y la respectiva gestión del proyecto (ejecución, supervisión, comercialización) y la segunda aportó la tierra. La alianza tuvo el rimbombante nombre de Ciudadela Nuevo Usme.

Parapetados jurídicamente en un nuevo Plan de Ordenamiento Territorial (POT) ${ }^{3}$, el cual define y reglamenta el uso de los suelos en la ciudad, se inicia la intervención del territorio de Usme. Para cumplir con plan de expansión urbana, Metrovivienda y la Secretaría de Hábitat instauran lo que se denominó la Operación Estratégica Nuevo Usme (OENU), la cual fue vista como una intervención urbana estratégica con el objetivo de transformar productiva, económica e urbanísticamente la localidad.

Para el año 2003 Metrovivienda inició el proyecto urbanístico y, en compañía de las Secretarías de Integración Social, Salud, Hábitat, Medio Ambiente, el hospital de Usme y el Jardín Botánico, inició diálogos con los habitantes de la localidad para evaluar los alcances de la iniciativa. Estos diálogos se dieron a través de mesas de trabajo tendentes a las posturas de cada actor y precisar en detalle los alcances del proceso. Dentro de los diálogos se estipuló que se respetarán las fuentes hídricas, así

3 El POT es aprobado en el año 2000 por el Gobierno Distrital, a través del decreto 619. 
como la "infraestructuras y servicios que faciliten la producción formal del suelo con urbanismo" (Contraloría, 2012, p. 8).

La expansión urbana se inició comprando los predios en los barrios ilegales; se realizó la demolición y la respectiva reubicación de las familias del proyecto Ciudad Nuevo Usme. A raíz de esto, se presentaron conflictos en torno a la percepción de desalojo forzado de las familias de la localidad, porque las viviendas que se les iba a entregar a los habitantes, según los líderes comunitarios, no compensaban las necesidades. También se discutió el valor de los inmuebles, pues la percepción de los pobladores de Usme no correspondía al valor que se le daría comercialmente. Para el 2006 Metrovivienda adquirió los terrenos de la Hacienda El Carmen, abarcando 30 hectáreas del territorio entre el barrio El Oasis y el pueblo fundacional de Usme; el terreno también abarcó las veredas campesinas Requilina y Uval. Las hectáreas estaban consideradas para la construcción de apartamentos para familias de escasos recursos, familias desplazadas y familias que habitaban en zonas de alto riesgo geográfico.

\section{Conflictos A RAÍZ DEL HALlazgo ARQUEOLÓGICO eN la hacienda El Carmen}

En el año 2007, cuando Metrovivienda adelantaba el proceso de adecuación de suelos en el terreno de la hacienda El Carmen, las máquinas hallan restos óseos y varios elementos como vasijas y collares. El hallazgo llevó a que líderes comunitarios como Jaime Beltrán y Juan Carlos Ocampo, realizaran la divulgación del descubrimiento ante las autoridades de la localidad (incluyendo las judiciales) y al Instituto Nacional de Antropología e Historia (ICANH). Su objetivo al denunciar el hallazgo fue el que se realizaran las respectivas indagaciones y se determinara el origen de lo encontrado.

"Yo lo hice público el día 9 o 10 de marzo del 2007 en una reunión de cultura con los campesinos sin tener las herramientas que se debian tener, pero generamos una comisión de trabajo para el día 12 de marzo. Ese día estuvimos en la hacienda El Carmen con el antropólogo Andrés Mesa y él nos confirma que existe una necrópolis dada las dimensiones y el área del terreno. Entonces desde ese momento, yo genero 
un documento hacia la alcaldia local de Usme, pidiendo si se habia hecho el plan previo de manejo arqueológico en la zona y los estudios correspondientes sobre el tipo de magnitud de esta obra; y es alli en donde comienza todo el descubrimiento de la Hacienda El Carmen’".

La denuncia frena el proceso que adelantaba Metrovivienda en la Hacienda el Carmen y permite que afloren varias inconformidades de los habitantes, así como de las organizaciones sociales y ambientales en relación con el proceso de expansión urbana. Es entonces como el hallazgo se convierte en una excusa para denunciar las inconformidades presentadas por los distintos actores, las cuales rechazan la construcción de nuevas viviendas y el desalojo de los barrios de alto riesgo.

Las entidades distritales decidieron frenar la expansión en el territorio para realizar el respectivo estudio, liderado por Metrovivienda y el departamento de Antropología de la Universidad Nacional de Colombia a través del investigador Virgilio Becerra. Cuando la evidencia arqueológica confirma la existencia de un antiguo cementerio Mhuysqa, los líderes de la comunidad convocan a los líderes de las comunidades aborígenes de Bogotá para realizar un trabajo mancomunado que posibilitara una definición estratégica frente al territorio. Sin embargo, la participación de los Mhuysqas fue rechazada por algunos sectores dado que en Usme no existen cabildos indígenas reconocidos por el Ministerio del Interior.

Mientras ello ocurría, la Universidad Nacional de Colombia desarrolló un plan de manejo para preservar el sitio y volverlo un parque arqueológico o un museo. La decisión no dejó conformes ni a las comunidades de Usme ni a los indígenas, pues no se sintieron ni legitimados ni representados en los documentos oficiales que definían el plan.

Un ejemplo de ello, son las palabras del Chiquy de Pueblo Nación Muisca Chibcha, Sigifredo Niño, dadas al Observatorio del Patrimonio Cultural y Arqueológico (OPCA) en agosto de 2009, a quien le preguntan por el papel de las comunidades

4 Entrevista a líder campesino Jaime Beltrán, realizada por los estudiantes del programa de Comunicación Social de la Universidad Santo Tomás Tatiana Ramírez, Andrea Gómez y Jean Carlo Felizzola en el ańo 2012. 
frente a su participación en los procesos que ha atravesado el hallazgo. El abuelo afirmó que lo mínimo (en nivel de participación) es que la comunidad Mhuysqa pueda realizar una ceremonia de pagamento en el lugar para así restituir espiritualmente el territorio y pedir permiso a los abuelos ancestrales del territorio para luego sí poder trabajar allí.

El Observatorio de Patrimonio Cultural y Arqueológico (OPCA) consulta, entonces, al ICANH su opinión y postura frente a lo expresado por el Abuelo Sigifredo. El instituto responde haciendo la claridad de que el patrimonio arqueológico pertenece a todos los y las colombianas y que, por lo tanto, las investigaciones que se hagan sobre este campo deben tener en cuenta los sentidos de pertenencia que las comunidades indígenas y los ciudadanos en general establezcan con respecto al territorio y los elementos allí encontrados. Sin embargo, las comunidades no pueden "infringir los principios constitucionales respecto a que el territorio es inembargable, imprescriptible, invendible e inalienable", así como tampoco obstruir las investigaciones sobre el lugar.

En el año 2009 se ejecuta una segunda fase del estudio, esta vez dirigida solo por la Universidad Nacional de Colombia. Por su parte, Metrovivienda cedió los predios a la Secretaría de Cultura y Recreación y Deporte (SCRD) para iniciar la ejecución del plan de manejo; sin embargo, no se conformó un equipo de trabajo para dicho propósito que vinculara a las comunidades. Por lo anterior, el conflicto, presentado por la monopolización del saber y la gestión patrimonial por parte de las instituciones se agudizó.

En ese mismo 2009 las autoridades distritales dan a conocer la Operación Estratégica Nuevo Usme, iniciando negociaciones para la construcción de la avenida Usminia, la cual atravesaría las quebradas Fucha, Piojo y Taza. La decisión repercute en los habitantes de Usme y en las organizaciones ambientales, ya que la construcción de la vía causará, en el decir de las organizaciones comunitarias, dańos ambientales irreversibles, puesto que Usme, junto con la región del Sumapaz, se considerada como una de las fuentes hídricas importantes para la ciudad. Las quejas y malestares surten efecto, y en el año 2010 se lleva a cabo las obras de construcción, pero cuidando las 
tres quebradas. Paralelo a ello se aprueba el plan parcial para la Hacienda El Carmen a través del decreto $54^{5}$.

En los años más recientes, el grupo Aval, uno de los más importantes del sector financiero en el país, inicia proyecto de construcción de casas de interés social en los predios de Metrovivienda, lo que agudiza la resistencia de los líderes y organizaciones de Usme en la lucha por la defensa del territorio.

\section{El PATRIMONIO COMO EXCUSA PARA LA DEFENSA DEL TERRITORIO}

Un sector de los habitantes de la localidad de Usme encontraron en el hallazgo arqueológico de hacienda $\mathrm{El}$ Carmen un pretexto para intervenir política y socialmente en las luchas por el territorio, apoyados por agentes externos como la Universidad Santo Tomás, por medio de la Unidad de Proyección Social.

En primera instancia, esta defensa emerge en tanto las comunidades sienten una instrumentalización del territorio, al convertirlo en una mercancía ficticia (Polanyi, 2001, p. 56) que monopoliza los intereses de un capital representado por las empresas constructoras. En términos de Leferbvre es "el espacio y por el espacio donde se produce la reproducción de las relaciones de producción capitalista. El espacio deviene cada vez más un espacio instrumental" (1974, p. 222). En ese panorama, el territorio se ve como un instrumento de dominación que organiza y explota la riqueza del mismo para las fuerzas capitales productivas. Y a raíz de ello, los habitantes manifiestan que la intención de las entidades distritales es "localizar a los pobres" para aprovechar los recursos con los que el territorio cuenta; también su denuncia radica en que se desconoce los procesos sociales que se dan en torno al mismo, la falta de respeto por la vida campesina y la falta de inclusión de los habitantes. Es por ello que,

5 El decreto estipula lo siguiente: "definir las condiciones urbanisticas y de gestión para el desarrollo urbano de un área que integre el parque y Museo Arqueológico de los hallazgos indígenas de Usme con las zonas de usos residenciales para vivienda de interés social y prioritario y articule la propuesta de estructuración de los planes parciales que hacen parte de la Operación Estratégica Nuevo Usme”. 
varias organizaciones sociales ${ }^{6}$ de la localidad, gestionan y realizan proyectos para generar un sentido de pertenencia entre los demás habitantes, con el fin de detener los proyectos de expansión urbana. En esta misma línea interviene la comunidad Mhuysqa, ya que para ellos el territorio no se concibe tanto como una valorización o apropiación de carácter instrumental-funcional, sino a una apropiación simbólicoexpresiva que incide en:

"como espacio de sedimentación simbólico-cultural, como objeto de inversiones estético-afectivas o como soporte de identidades individuales y colectivas. (...) el territorio es también objeto de operaciones simbólicas y una especie de pantalla sobre la que los actores sociales (individuales o colectivos) proyectan sus concepciones del mundo. Por eso el territorio puede ser considerado como zona de refugio, como medio de subsistencia, como fuente de recursos, como área geopolíticamente estratégica, como circunscripción político-administrativa, etcétera; pero también como paisaje, como belleza natural, como entorno ecológico privilegiado, como objeto de apego afectivo, como tierra natal, como lugar de inscripción de un pasado histórico y de una memoria colectiva" (Giménez, 2000, p. 24).

Es así como el mismo grupo social es el encargado, a través de sus prácticas colectivas e individuales, de otorgarle una significación al territorio. En otras palabras: se reorganizan los sentidos para mostrar otras perspectivas para la preservación patrimonial de un territorio que es leído en clave de ancestralidad/espiritualidad. De acuerdo con estas perspectivas, el saber aporta en

"tanto a la comprensión, como al diagnóstico y la intervención social en éstas condiciones críticas. Pero deben asumir el desafio de producir un saber a la vez disciplinario e inteligible a la gente. Y también se debe desarrollar un "discurso del método" asociado a la práctica de la intervención, y la construcción de espacios de participación. La comunicación implica no solo al proceso de recreación de los vinculos y del lazo social. Implica su concreción en actos y en valores. La

6 Es el caso de la organización CASAASDOAS, la cual lucha por el reconocimiento del valor cultural y patrimonial del territorio de hacienda El Carmen, apropiando un discurso de memoria. 
comunicación —en tanto praxis— debe ser el lugar del sentido" (Vizer, 2002, p. 17).

En el año 2011 y paralelo a las luchas establecidas por los diferentes actores por el territorio, se elige un nuevo alcalde en la ciudad, Gustavo Petro, con la propuesta de La Bogotá Humana ${ }^{7}$, donde se replantea la expansión urbana y frena el crecimiento de la ciudad en los bordes periféricos. Este cambio de administración conllevó a que también los procesos de diálogo se efectuaran de una manera más eficaz. Las denuncias presentadas, tuvieron respuesta por parte del distrito, el cual manifestó encontrar errores por parte de Metrovivienda frente a la política sobre uso y ocupación del suelo en la ciudad.

Quizá el avance más importante con el cambio de administración es que se garantiza una mayor participación ciudadana que garantiza, por un lado, revalorizar la noción instrumental del territorio y, por otro, resignificar las implicaciones sociales de lo que encierra o envuelve la palabra patrimonio. El patrimonio adquiere una dimensión cultural y social que reconoce procesos de creación de sentido y de representación. De acuerdo con Jene Smith (2011) el patrimonio puede ser entendido útilmente como una representación subjetiva, en la que identificamos los valores, la memoria y los significados culturales y sociales que nos ayudan a dar sentido al presente, a nuestras identidades, y otorgan una sensación de lugar físico y social.

\section{LA MEMORIA: INSTRUMENTO PARA COMPRENDER EL SENTIDO ANCESTRAL MHUYSQA}

En la lectura que las comunidades Mhuysqa hacen del cementerio ${ }^{8}$ hallado en hacienda El Carmen cabe resaltar la lectura respecto al retorno de los cuerpos de los abuelos a sus tumbas, entendiendo la importancia del lugar en tanto el sitio tiene,

7 Es el caso de la organización CASAASDOAS, la cual lucha por el reconocimiento del valor cultural y patrimonial del territorio de hacienda El Carme, apropiando un discurso de memoria.

8 Cementerio o Chamandunavo significa, para la comunidad Mhuysqa, Madre de la sabiduría de semilla de ancestros espirituales. 
según la lectura ancestral, una fuerte "conexión para alimentar el espiritu y el cuidado del territorio, ya que sólo los mayores descansaban en la Madre, donde la semilla espiritual era más fuerte. Hay que protegerlo y cuidarlo desde el canto, la danza y la medicina. Este lugar es la sabiduria de la semilla del pensamiento, era un lugar no habitado, era un lugar de paso, donde los ancestros recogían la semilla de abundancia para el recorrido que debian emprender a otros santuarios del territorio Mhuysqa" (Cabildo Mhuysqa de Bosa, 2013, p. 60).

La defensa por el territorio que configura Hacienda El Carmen, así como las diferentes voces que lo reclaman, se visibiliza con mayor fuerza en la construcción identitarias y de pertenencia por medio de un ejercicio de recordación, el cual imbrica un ejercicio de construcción memoria cultural (Assmann, 2006, p. 32). En esa construcción de memoria también subyacen disputas políticas y sociales por los sentidos que emergen para la comprensión de pasado en relación con el territorio. Esas disputas se expresan en dos escenarios esenciales:

Una primera disputa está, precisamente, en las versiones entre las distintas comunidades (aborígenes, organizaciones sociales comunitarias, pobladores urbanos y pobladores rurales de Usme) con el conocimiento científico que se construye desde el trabajo investigativo que lidera la Universidad Nacional, representado por Virgilio Becerra. Una lectura sobre esa disputa podría suponer que la producción institucional dispone una interpretación "oficial”, amparada en un lenguaje científico arqueológico, que discute las versiones que, a partir de la memoria, tienen las comunidades respecto al territorio. No obstante, más que una discusión por sentidos del pasado lo que existe es la clásica tensión entre la facticidad empírica que se erige a través del dato objetivo en el proceso del trabajo científico y la subjetividad de un recuerdo en constante mutación, en tanto la narrativa se reactualiza sobre la base de los intereses políticos y sociales tanto presentes como futuros. De cualquier modo, la disputa posibilitó un encuentro entre actores que dio como resultado el catapultar la posición respecto a que el hallazgo debe traducirse en conservación y protección del territorio, incluyendo la pretensiosa idea de que esa protección se extienda a todo el borde rural de la localidad. Es bastante probable que con un cambio de administración, la llegada de Enrique Peńalosa Londoño como burgomaestre de la ciudad en el periodo 2016 a 2020, la aspiración de los constructores por extender a 
todas las áreas rurales de la ciudad de Bogotá sus proyectos de vivienda se vuelva a consolidar como la proyección oficial de un nuevo POT.

El otro escenario de disputa está entre las comunidades de la localidad de Usme, con su consigna sobre la defensa del territorio frente a una política de expansión urbana, y las comunidades aborígenes Mhuysqa que también asumen la defensa del territorio desde una perspectiva ancestral. En consecuencia, las comunidades aborígenes buscan resaltar la importancia del hallazgo desde un sentido más espiritual, anclado a saberes ancestrales, que, a la luz de los intereses políticos y sociales de las organizaciones, no resultan de interés en la agenda actual de los pobladores de Usme.

\section{A MODO DE CONCLUSIÓN: ENCUENTROS Y DESENCUENTROS}

El ejercicio investigativo con los distintos actores que convergen en torno al hallazgo arqueológico de hacienda El Carmen en la localidad de Usme permitió comprender unas realidades que trascienden el asunto del manejo político y cultural que se le debe otorgar a un cementerio aborigen desde la perspectiva patrimonial. En el hallazgo del cementerio subyace una discusión bastante compleja y para nada agotada sobre la expansión urbana de la ciudad de Bogotá hacia las áreas o bordes rurales. En consecuencia, el recorrido investigativo permitió colegir los siguientes puntos para futuras discusiones:

1. Los diferentes actores involucrados en el hallazgo arqueológico — campesinos, organizaciones sociales, ambientales y las comunidades indígenas-, proponen planes de manejo en el territorio que, no obstante, todavía no han sido concretados en decisiones administrativas que en verdad garanticen la preservación del territorio. Quizá sea este el punto más controversial y complejo en el tiempo venidero, dado que esas garantías no dependen del agenciamiento comunitario sino de las voluntades de unas administraciones cambiantes que arriban a las realidades sociales con sus propios intereses y agendas. Dado que las comunidades comprenden esas dinámicas políticas, ligadas a compromisos electorales de los mandatarios de turno, los ejercicios de memoria —que resignifican políticamente las interpretaciones sobre 
el territorio y (re)actualizan las nociones propias sobre lo patrimonial-, deben acentuarse para no sucumbir frente a unas agendas económicas que, parafraseando a Polanyi, se imponen sobre las dinámicas sociales.

En ese contexto, la mesa de concertación de borde urbano rural de Usme sigue recogiendo la visión comunitaria para elaborar propuestas de planificación territorial, que incluyen al cementerio como punto arqueológico, con miras a seguir velando por la conservación del hallazgo. Sin duda alguna, el cementerio es y será el clivaje para continuar discutiendo con las entidades distritales el futuro de un territorio geoestratégico para los intereses de la ciudad de Bogotá, en un horizonte que contrapone las dinámicas de expansión urbana con las acciones comunitarias de protección ambiental.

2. Por otra parte, es bastante probable que las tensiones por la monopolización del conocimiento y el saber se mantengan, lo cual implicará procesos de agenciamiento y negociación entre los distintos actores de cara a la manera como las mismas agendas también se reconfiguren en el contexto político. Desde la perspectiva tanto institucional como comunitaria se debería privilegiar una estrategia incluyente y participativa de todos los actores involucrados en el proceso. En ese contexto, se debe hacer hincapié en la participación de los representantes del pueblo Mhuysqa, a pesar que no tengan asiento político en el ámbito local. El desconocimiento de este pueblo originario en los procesos comunitarios y políticos puede llegar a traducir en una eventual demanda por la violación a la ley 21 de 1992 que estipula, a la luz del convenio 169 de la Organización Internacional de Trabajo, la obligatoria consulta con las autoridades tradicionales, cuando en el territorio propio y/o ancestral se desarrollen acciones que impacten al pueblo aborigen. Ello en consonancia con el reconocimiento constitucional de un país que se autoproclama como pluricultural y pluriétnico. Es así como en el marco de las políticas públicas de la ciudad, la Secretaría Distrital de Integración Social determina:

"Reconocer la diversidad cultural, proteger y restablecer los derechos fundamentales, colectivos e individuales, asi como sus aportes históricos y culturales a través de un proceso participativo de diálogo. El análisis de la situación de los pueblos indígenas 
en el Distrito Capital se debe abordar teniendo en cuenta su dimensión de sujetos colectivos, bajo una lectura histórica, ambiental y política de las dinámicas sociales en el ámbito local, por lo cual cualquier acción estatal requiere la comprensión de sus cosmovisiones, su identidad, su riqueza ancestral y sus expresiones culturales, plasmadas en sus planes de pervivencia y permanencia cultural" (Secretaría Distrital de Integración Social, 2011).

A pesar de este reconocimiento, las mismas comunidades aborígenes optaron por ahondar en diferentes estrategias de agenciamiento, destacando el ejercicio de recuperar la memoria cultural ${ }^{9}$ del pueblo Mhuysqa. El trabajo de memoria tiene como eje central la (re)significación del territorio, anclado a la cosmovisión, a la cosmogonía y a la ley de origen del pueblo ${ }^{10}$.

3. Mientras las entidades del Distrito tienen como basamento para la construcción del plan de manejo del cementerio, los campesinos y líderes comunitarios plantean una gestión autónoma del territorio, en la que se imagina una eventual administración compartida entre el Distrito, las organizaciones sociales comunitarias y el pueblo Mhuysqa. Los líderes del pueblo Mhuysqa, por su parte, abogan por el respeto a un territorio que consideran como un lugar de descanso de los mayores, en la reposan, además, todas las energías que confluyen en el territorio. En lo que atañe a la propuesta diseñada en Usme por los habitantes del borde urbano/rural está direccionada a una construcción social del territorio que no esté centrada en la expansión urbana. Frente al cementerio se proponen aspectos como: a) formar a la comunidad

9 Se retoma la categoría de Jan Assmann en la que se entiende que la memoria tiene una base social pero también una base cultural que franquea la oposición que Halbwachs estableció entre memoria y "tradición”, pues para Assmann la tradición también forma parte de la memoria en tanto tiene la función de mantener vivo unos recuerdos que no tienen un sustento en la vida cotidiana $(2006,28)$.

10 Desde la cosmogonía Mhuysqa se entiende por Ley de Origen como el orden establecido desde un principio, desde antes de la creación o antes del amanecer. Es el orden natural en la cual el ser humano no ha intervenido, pues es anterior a su existencia. También se puede entender como matriz mental que constituye la base de lo que se manifestó y apareció en diversidad natural y cultural. Desde allí se dejó ordenado todo lo que existe: cada pueblo y cada cultura es hija de la Ley de Origen, todo se origina allí. La cultura, por tanto, no es creación humana. Esta se transforma, se recrea y se fortalece, pero existe un mandato original, una base que no es humana. Desde allí se originan las diferentes lenguas, los mitos y las maneras culturales básicas (Cabildo Mhuysqa, 2013). 
frente al manejo del sitio arqueológico a partir de un nodo educativo, cultural y turístico de Usme; b) la libración de los predios de la quebrada La Fucha y demás terrenos aledaños a la hacienda, c) establecer redes con organizaciones, instituciones, colegios, entre otros actores, para impulsar en los jóvenes de las comunidades la importancia del hallazgo arqueológico; d) abrir la participación al sector académico e investigativo que posibilite la participación y la generación de propuestas de investigación arqueológica, etnohistórica y antropológica alrededor de Usme, explorando rutas metodológicas colaborativas que logren materializar propuestas como el diseño de rutas pedagógicas/turísticas.

4. Con los cambios en la política por cuenta de los mandatarios de turno, es prioritario pensar en planes de manejo sobre los terrenos de hacienda El Carmen que incluyan las propuestas de la comunidad indígena, así como de las comunidades y organizaciones que representan a los pobladores de la localidad de Usme. Sin duda alguna, el liderazgo de la gestión debe estar en cabeza del Instituto Distrital de Patrimonio Cultural, encargado de la gestión del hallazgo luego de la declaratoria de patrimonio. No obstante, hasta la fecha no se ha establecido contacto con los cabildos indígenas ni con las organizaciones para dar cumplimiento a un mínimo ejercicio de consulta. Pese a la situación, para el caso de las comunidades indígenas se mantiene el objetivo de un manejo del territorio que respete la ley de origen y las ordenanzas del territorio, lo que implica que no pueden realizarse construcciones en el lugar, porque allí descansan los abuelos... los ancestros. En ese sentido, las peticiones son muy concretas y precisadas: 1) la inclusión de los saberes del pueblo Mhuysqa en la interpretación del hallazgo; 2) el tener acceso libre al lugar; 3) el contar con un escenario para realizar las ceremonias de pagamento; 4) el consultar la hoja de ruta en el manejo del cementerio como patrimonio; 5) la no exploración de las tumbas; 6) finalmente, retornar los elementos y cuerpos extraídos.

5. En consonancia con lo anterior, las comunidades y organizaciones aborígenes, en cabeza de los cabildos y respaldados por la Organización Nacional Indígena de Colombia (ONIC), no descartan la posibilidad de demandar al gobierno nacional por desacato el cumplimiento de la debida consulta previa con las autoridades del pueblo Mhuysqa. 
6. Trascendiendo los intereses políticos en las disputas entre pobladores y organizaciones de Usme con las comunidades aborígenes, hay que resaltar que no todas las propuestas de manejo del territorio han sido aisladas. La evidencia investigativa permitió encontrar puntos en los cuales los actores convergen. Ambos, por ejemplo, velan por el respeto a los recursos ambientales, sobre todo hídricos, y a las proyecciones de expansión urbana de la ciudad de Bogotá sobre las amplias áreas rurales tanto de Usme como de Sumapaz. Desde sus particulares concepciones también van en contra de la explotación del territorio, distanciándose de la perspectiva desarrollista que cosifica para mercantilizar. Ahora bien, frente al hallazgo del cementerio, los dos actores tienen puntos de encuentro en cuanto a las concepciones del patrimonio en el territorio, ya que para los dos el cementerio adquiere nuevos significados más allá de los datos "históricos", apropiando el carácter patrimonial como aparato ideológico. Me explico: trascendiendo la (re)significación del territorio desde los ejercicios de memoria, los cuales afianzan la idea de un territorio como escenario simbólico/cultural, las comunidades buscan evitar la expansión urbana por parte de constructores que instrumentalizan el territorio; de hecho, el sentido común lleva a colegir que para los constructores la noción de "territorio" no existe en términos sociológicos, pues su lógica mercantil lo lleva a concebir el espacio como una mercancía representada en el valor de lo que representa la "tierra". 


\section{REFERENCIAS}

Assmann, J. (2006). Religion and cultural memory. Stanford: Stanford University Press.

Contraloría de Bogotá (2012). Informe final de visita fiscal. Seguimiento a los cronogramas de actividades de la Operación Estratégica Nuevo Usme. Recuperado de http://www. contraloriabogota.gov.co/intranet/contenido/informes/AuditoriaGubernamental/Control_Urbano/PAD_2012/CicloIII/Operacion\%20estrategica\%20Nuevo\%20Usme.pdf

Cabildo Indígena Mhuysqa de Bosa (2013). Retornando por el camino de los antiguos. Bogotá: Alcaldía Mayor de Bogotá.

Giménez, G. (2000), Territorio, cultura e identidades. México: Editorial Porrua.

Integración Social (2011). Formulación participativa de la política pública distrital para el reconocimiento, garantía, protección y restablecimiento de derechos de los pueblos indígena en Bogotá. Recuperado de http://old.integracionsocial.gov.co/anexos/documentos/ polpublicas/pol\%C3\%ACtica\%20ind\%C3\%ACgena.pdf

Lefebvre, H. (20134 [1974]). La producción del espacio. Madrid: Capitán Swing Libros.

Polanyi, K. (2001). La gran transformación. Los origenes politicos y económicos de nuestro tiempo. México. FCE.

Smith, J. (2011). El "espejo patrimonial".'illusión narcisista o reflexiones múltiples?. En Antípoda (12): pp. 39-63.

Vizer, E. (2002). La trama (in)visible de la vida social: comunicación, sentido y realidad. Buenos Aires: EUDEBA. 